\title{
Ischemic colitis following routine screening colonoscopy: a case report
}

Ischemic colitis is a condition commonly seen in the elderly and individuals with risk factors for ischemia. However, a rare cause of ischemic colitis is colonoscopy. We report a case of ischemic colitis after a routine screening colonoscopy in a patient with no risk factors for ischemia.

A 55-year-old man with no prior medical history presented to the emergency room complaining of mild lower abdominal pain and bloody bowel movements following a routine screening colonoscopy. He reported no history of recreational drug or nonsteroidal anti-inflammatory drug use. The screening colonoscopy findings were normal ( $\bullet$ Fig. 1), and the procedure itself had been uneventful. Plain abdominal radiography revealed no evidence of free air. A repeat colonoscopy showed active colitis limited to the splenic flexure ( Fig. 2, 3). Biopsies showed nonspecific mucosal edema. The patient was managed supportively and his symptoms resolved.

Colonoscopy is a very rare cause of ischemic colitis. Only five reports have been published in the English literature to date. Four case reports cited predisposing factors for ischemia, such as chronic hypertension and systemic lupus erythematosus $[1,2]$. The fifth article did not comment on the comorbidity of the patient [3]. Although biopsy specimens from our patient revealed nonspecific edema, we believe that the distribution of inflammation and the clinical presentation were consistent with ischemic colitis. We believe our case to be unique due to the lack of prior history of vascular compromise, leaving the only predisposing factor for ischemic colitis to be the colonoscopy itself.

The mechanism of injury due to colonoscopy is thought to be reduced blood flow and oxygen to the colonic wall secondary to increased intraluminal pressure during the colonoscopy and decreased intravascular volume from fasting and colon preparation $[4,5]$. The treatments for ischemic colitis include supportive care

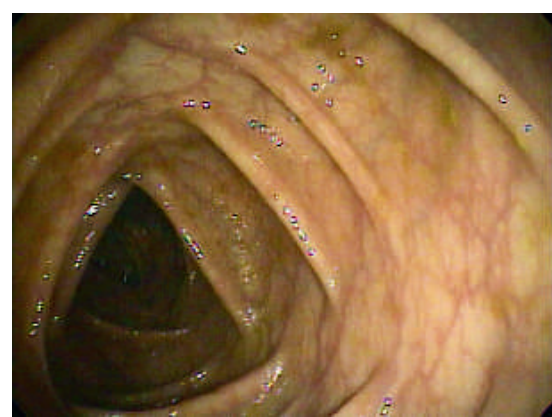

Fig. 1 Normal colonic mucosa during initial colonoscopy.

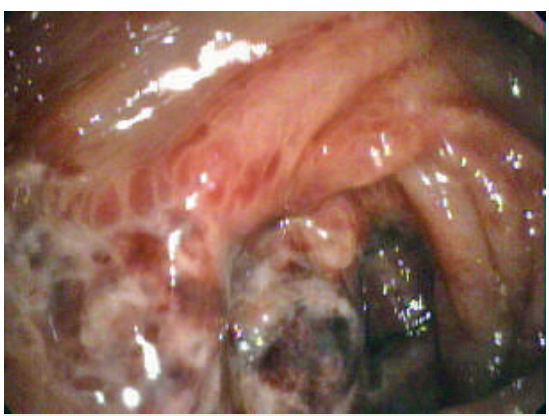

Fig. 2 Active colitis seen at the splenic flexure.

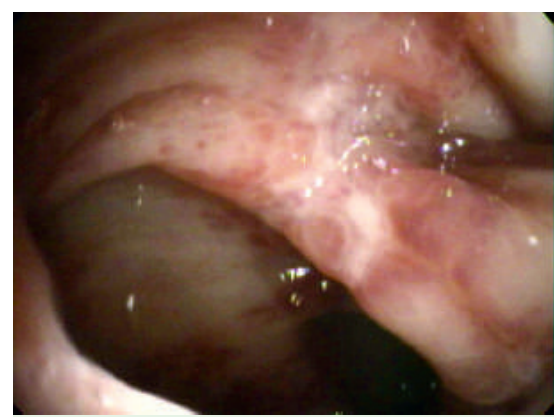

Fig. 3 Active colitis seen at the splenic flexure.

and monitoring for possible complications. Most patients with ischemic colitis show clinical improvement within $24-$ 48 hours with appropriate treatment.

Endoscopy_UCTN_Code_CPL_1AJ_2AB

\section{K. T. Kao, A. Jain, A. Sheinbaum}

Department of Internal Medicine, Gastroenterology Division, Southern California Kaiser Permanente Medical Group, Los Angeles, California, USA

\section{References}

1 Nozawa H, Akiyama Y, Sunaga S, Tsurita G. Ischemic colitis following colonoscopy in an elderly patient on cardiovascular medication. Endoscopy 2007; 39 (Suppl 1): E344-E345

2 Church JM. Ischemic colitis: complicating flexible endoscopy in a patient with connective tissue disease. Gastrointest Endosc 1995; 41: 181 - 182

3 Weeldon NM, Grudman MJ. Ischemic colitis as a complication of colonoscopy. Br Med J 1990; 301: 1080-1081

4 Cremers MI, Oliveira AP, Freitas J. Ischemic colitis as a complication of colonoscopy. Gastrointest Endosc 1998; 30: S54

5 Versaci A, Macri A, Scuderi $G$ et al. Ischemic colitis following colonoscopy in a systemic lupus erythematosus patient: report of a case. Dis Colon Rectum 2005; 48: 866- 869

Bibliography

DOI 10.1055/s-0028-1119622

Endoscopy 2009; 41: E100

(c) Georg Thieme Verlag KG Stuttgart · New York . ISSN 0013-726X

Corresponding author

\section{K. T. Kao, MD}

Department of Internal Medicine

Gastroenterology Division

Southern California Kaiser Permanente

Medical Group

1526 North Edgemont St.

Los Angeles

CA, 90027

USA

Fax: +1-323-783-7056

Kevin.t.kao@kp.org 